\title{
Reversine suppresses oral squamous cell carcinoma via cell cycle arrest and concomitantly apoptosis and autophagy
}

\author{
Ying-Ray Lee ${ }^{1,2+}$, Wei-Ching $\mathrm{Wu}^{3 \dagger}$, Wen-Tsai $\mathrm{Ji}^{3}$, Jeff Yi-Fu Chen ${ }^{4}$, Ya-Ping Cheng ${ }^{3}$, Ming-Ko Chiang ${ }^{3}$ and \\ Hau-Ren Chen $^{3 *}$
}

\begin{abstract}
Background: The effective therapies for oral cancer patients of stage III and IV are generally surgical excision and radiation combined with adjuvant chemotherapy using 5-Fu and Cisplatin. However, the five-year survival rate is still less than 30\% in Taiwan. Therefore, evaluation of effective drugs for oral cancer treatment is an important issue. Many studies indicated that aurora kinases (A, B and C) were potential targets for cancer therapies. Reversine was proved to be a novel aurora kinases inhibitor with lower toxicity recently. In this study, the potentiality for reversine as an anticancer agent in oral squamous cell carcinoma (OSCC) was evaluated.
\end{abstract}

Methods: Effects of reversine on cell growth, cell cycle progress, apoptosis, and autophagy were evaluated mainly by cell counting, flow cytometry, immunoblot, and immunofluorescence.

Results: The results demonstrated that reversine significantly suppressed the proliferation of two OSCC cell lines (OC2 and OCSL) and markedly rendered cell cycle arrest at G2/M stage. Reversine also induced cell death via both caspase-dependent and -independent apoptosis. In addition, reversine could inhibit Akt/mTORC1 signaling pathway, accounting for its ability to induce autophagy.

Conclusions: Taken together, reversine suppresses growth of OSCC via multiple mechanisms, which may be a unique advantage for developing novel therapeutic regimens for treatment of oral cancer in the future.

Keywords: Reversine, cell cycle arrest, apoptosis, autophagy, oral squamous cell carcinoma (OSCC)

\section{Background}

Oral cancer is listed as the sixth common tumor worldwide [1]. In Taiwan, oral cancer is even the fourth leading cause of cancer death for males [2]. Oral squamous cell carcinoma (OSCC) is the most common neoplasia and is found frequently in oral cavity such as cheek, gum, and tongue [3]. Although cigarette and alcohol are considered as two major risk factors of oral carcinogenesis [4], occurrence of oral cancer was proved to be tightly associated with betel quid chewing in Taiwan and in south-east Asia [4,5]. So far, surgery and radiation treatments in combination with chemicals like 5-Fu

\footnotetext{
* Correspondence: biohrc@ccu.edu.tw

† Contributed equally

${ }^{3}$ Department of Life Science, Institute of Molecular Biology and Institute of Biomedical Science, College of Science, National Chung Cheng University, Min-Hsiung, Chia-Yi, Taiwan

Full list of author information is available at the end of the article
}

or Cisplatin are the major therapeutic strategies for oral cancers $[6,7]$. However, surgery and radiation treatments inevitably cause negative impacts on patients' appearance and oral functions like chewing and speaking. In spite of $5-\mathrm{Fu}$ or Cisplatin adjuvant treatments, 5 years survival rate of oral cancer patients is only $30 \%$ [6]. A more efficient and safer anticancer drug may be helpful to minimize the surgery area or to delay disease progress.

Aurora kinase, which includes A, B and C members in mammals, is belonged to serine/threonine kinase. Aurora kinase $\mathrm{A}$ and $\mathrm{B}$ were demonstrated to function at mitosis. Like some cell cycle regulators, expression of aurora kinase $\mathrm{A}$ and $\mathrm{B}$ oscillates during cell division $[8,9]$. Aurora kinase A controls the entrance into mitosis by regulating cyclin B/CDK1 [10]. Aurora kinase B phosphorylates Ser10 on Histone $\mathrm{H} 3$ to regulate 
chromosome condensation and interacts with INCENP, survivin, and borealin to form chromosomal passenger complex for chromosome arrangement during cytokinesis [11-14]. Aurora kinase $C$ is mainly expressed in testis and is involved in spermatogenesis [15,16]. Several studies had implicated the relationship between aurora kinases and carcinogenesis [17]. Overexpression of aurora kinase A produces several centrosomes in fibroblast, resulting in aneuploidy [11]. Both aurora kinase A (also named as STK15) and B had been suggested to be correlated with oral cancer $[18,19]$. Despite its major expression site in testis, aurora kinase $\mathrm{C}$ appears occasionally in some cancer tissues [20].

Currently, aurora kinases inhibitors VX680 and PHA730358 are clinically tested [21,22]. In Myc-overexpressed cells, treatment of VX680 was reported to induce apoptosis or the subsequent autophagy-mediated death in residual cells [23]. Autophagy is a mechanism by which cells enhance metabolism of damaged organelles or recycle dispensable materials to survive harsh conditions like starvation. In the initiation of autophagy, LC3 (type I) could be lipidated and became active form (type II), which would interact with cellular lipid to facilitate aggregation of autophagosome [24]. Therefore, VX680 treatment induces both apoptosis and autophagy, leading to increase the chance of oncolysis. Based on the fact that VX680 successfully interferes with growth of various malignant cell lines obtained from different tissues [25], aurora kinases become valuable targets for cancer therapies. Therefore, it is important to identify effective inhibitors for aurora kinases and understand the mechanisms for the inhibitory effects.

Reversine (2-(4-morpholinoanilino)-6-cyclohexylaminopurine) was found originally to promote cell dedifferentiation [26,27]. Recently, aurora kinases were proved to be the targets of reversine [28]. Compared with VX680, reversine is less toxic to cells from healthy donors but is efficient to reduce cell colony formation from acute myeloid leukemia (AML) patients. Besides, reversine was also proved to block proliferation or to induce programmed cell death in different malignant cell lines such as HCT-116 [29]. In vivo, reversine restricts tumor growth from xenograft models experiment $[29,30]$. These data increase the possibility that reversine may be a potential candidate for treating oral cancers. In this study, we investigate the mechanisms behind the suppressive effects of reversine on OSCC cells and conclude that reversine is a broad-spectrum agent involved in cell cycle arrest, apoptosis, caspaseindependent cell death and autophagy.

\section{Materials and methods}

\section{Cell culture and Transfection}

Two OSCC cell lines (OCSL and OC2), which were derived from two males with habits of drinking, smoking, and betel quid chewing in Taiwan, were maintained in RPMI1640 medium supplemented with 10\% fetal bovine serum (FBS) and 1\% penicillin/streptomycin. Cells were cultured at $37^{\circ} \mathrm{C}$ supplied with $5 \% \mathrm{CO}_{2}$. About $1.5 \times 10^{5}$ cells were seeded in 6-wells plates. Then, cells were transfected with Lipofectamine 2000 (Invitrogen) according to manufacturer's instruction.

\section{Reagents and antibodies}

Reversine was purchased from Cayman. Dimethyl sulfoxide (DMSO) and 3-methyladenine (3-MA) were from Sigma. Trypan blue was from BioWest. Z-VAD-fmk and wortmannin was from Merck. Antibodies against caspase $3,8,9$, phospho-aurora $\mathrm{A} / \mathrm{B} / \mathrm{C}, \mathrm{Cdc} 2, \mathrm{mTOR}$, phospho-mTOR, phospho-p70S6K, and rapamycin were from Cell Signaling. Antibodies against AIF, Bcl-xL and Bid were from Epitomics. Antibodies of total and phosphor-Akt were from Santa Cruz. Antibody against LC3 was from Abgent. Other antibodies were all from GeneTex.

\section{Cells viability analysis}

$1 \times 10^{5}$ cells were seeded into 6-wells plates. After chemicals treatment for indicated times, cells were collected by trpsinization, centrifuged, resuspended in $500 \mu \mathrm{l}$ PBS and stained with $0.5 \%$ trypan blue. The unstained cells were quantified using a counting chamber.

\section{Cell cycle analysis}

$1 \times 10^{5}$ cells were seeded in 6-wells plates and serum starved after attachment. After starvation, cells were treated with chemicals, harvested, washed once with 3 $\mathrm{ml}$ PBS, centrifuged, resuspended in $1 \mathrm{ml}$ PBS, and

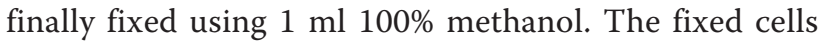
were air tightly stored in a $4^{\circ} \mathrm{C}$. Before analysis, cells were washed once with $3 \mathrm{ml}$ PBS, resuspended in $400 \mu \mathrm{l}$ PBS, transferred into a $15 \mathrm{ml}$ tube containing $78 \mu \mathrm{l} 1 \times$ PBS, $2.5 \mu \mathrm{l}$ RNase $(10 \mathrm{mg} / \mathrm{ml})$ and $20 \mu \mathrm{l}$ propidium iodide (PI, $1 \mathrm{mg} / \mathrm{ml}$ ). After incubation in dark for 30 minutes, treated cells were analyzed by BD CANTO II flow cytometer.

\section{Cell lysates preparation and Western blot}

Cells were lysed with M-PER (mammalian protein extraction reagent, Thermo) containing $0.1 \%$ protease inhibitor cocktail. Mixture was vortexed and incubated on ice for 5 minutes. After centrifugation at $14,000 \mathrm{~g}$ for 15 minutes at $4^{\circ} \mathrm{C}$, protein concentration in the supernatant part was quantified using BCA protein assay kit (Thermo). Proper amount of proteins was mixed with $5 \times$ Laemmli sample buffer and boiled for 10 minutes. Samples were run on SDS-PAGE gels and transferred to PVDF membranes. Specific targets were detected using proper antibodies, followed by the secondary antibody 
conjugated with horseradish peroxidase (HRP). After incubation with Immobilon Western Chemiluminescent HRP substrate (Millipore), the results were detected using BioSpectrum Imaging System (UVP).

\section{Dual staing of annexin $\mathrm{V}$ and propidium iodide (PI)}

$1 \times 10^{6}$ cells were seeded into $10 \mathrm{~cm}$ plates, treated with indicated chemicals, collected by centrifugation. The pellet cells were stained using Annexin V-FITC detection kit (Strong Biotech) and analyzed by flow cytometer.

\section{DNA fragmentation analysis}

The preparation of fragmented DNA was according the method described [31].

\section{Immunofluorescence}

Cultured cells were washed twice with PBS and fixed in ice-cold 4\% formaldehyde/PBS for 20 minutes. After washing three times with PBS again, cells were stained with anti-AIF antibodies at $4^{\circ} \mathrm{C}$ with gentle swirling overnight. Then, cells were incubated with second antibodies conjugated with Alexa 488 at room temperature. After washing, localization of AIF was observed using a fluorescence microscope.

\section{Confocal microscope}

$1.5 \times 10^{5}$ cells were seeded in 6 -wells plates preloaded with sterilized glass cover slips. After transfection and/ or chemicals treatment, cells on cover slips were washed twice with PBS and fixed with $4 \%$ paraformaldehyde for 30 minutes at room temperature. After washing three times with PBS, cover glasses were carefully mounted onto microscope glasses containing a drop of ProLong Gold antifade reagent with DAPI (Invitrogen). Finally, the slides were sealed and analyzed using Olympus confocal microscope.

\section{Results}

\section{Reversine suppresses the growth of OSCC cells}

To evaluate the potential effect of reversine on suppressing OSCC cell growth, two cell lines OCSL and OC2 cells established from the local patients were examined [32]. The endogenous levels of phosphorylated aurora kinases were detectable, implying the potential application of reversine for suppressing the growth of oral cancer cells (Additional file 1A). To prove that aurora kinase were inhibited in these two cell lines, Serine 10 phosphorylation of histone $\mathrm{H} 3$, which was proved to be a direct downstream target of aurora kinases, were evaluated $[29,33]$. Indeed, reversine obviously inhibited the Serine 10 phosphorylation of histone H3. This result suggested that reversine strongly inhibited aurora kinases in these two OSCC cells (Additional file 1B).
Therefore, the effects of reversine on proliferation of OC2 and OCSL were checked. As shown in Figure 1, 1 $\mu \mathrm{M}$ reversine was enough to suppress the growth of both cells. Higher doses of reversine further reduced cell numbers as early as 12 hours after treatment, indicating that reversine possessed the effective inhibition ability against the growth of OSCC cells.

\section{Reversine interferes with the progress of cell cycle}

Aurora kinases had been proved to play important roles in regulating cell division [34]. Inhibition of aurora kinases resulted in cell cycle arrest or even cell death $[35,36]$. To examine whether the cell cycle was affected, OC2 and OCSL cells were analyzed by flow cytometry after treating with various doses of reversine at different time points. The results were shown in Figure 2B. Basically, the percentage of $\mathrm{G} 2 / \mathrm{M}$ cells increased with the high doses $(10 \mu \mathrm{M})$ of reversine (Figure 2A upper panel). Taken In addition, the ratio of cells with $4 \mathrm{~N}$ chromatin increased significantly in a dose- and timedependent pattern (Figure 2B). Moreover, some cells with $8 \mathrm{~N}$ chromatin were also noticed in OCSL cells, highly suggesting that reversine delayed progress of cell cycle and affected the processes of cytokinesis. To further support this notion, we checked the effect of reversine on the expression of cyclin B1. Reversine appeared to prolong the expression of cyclin B1 in synchronized OCSL and OC2 cells (Figure 2C). It is known that the expression of cyclin D1 is required for next cell cycle entry from $M$ phase. Indeed, in the absence of reversine treatment (DMSO mock treatment), the levels of cyclin D1 proteins were up-regulated after 9 hours. In contrast, reversine treatment had suppressed the protein level of cyclin D1 throughout the treating period (Figure 2C). In addition, the levels of Cdc2, a CDK of $\mathrm{G} 2 / \mathrm{M}$, were not significantly influenced by reversine (Figure 2C). Taken together, these results indicated that reversine caused retardation at G2/M phase in the cell cycle. Moreover, reversine also highly increased subG1 population after 48 hours treatment (Figure 2A lower panel and $2 \mathrm{~B}$ ), suggesting a possibility that reversine induced cytotoxic effects at the later stage.

\section{Reversine induces cell death through canonical and non- canonical apoptosis pathways}

The increased subG1 population suggested growth suppression through programmed cell death. Therefore, OSCC cells were dually stained with annexin V-FITC and with propidium iodide (PI) to monitor type I programmed cell death (apoptosis) in the absence or presence of reversine. Treatment of reversine increased the population of annexin V positive and PI-positive cells in a time- and doses-dependent manner as shown in Figure 3A. Especially, the apoptosis percentage was over 


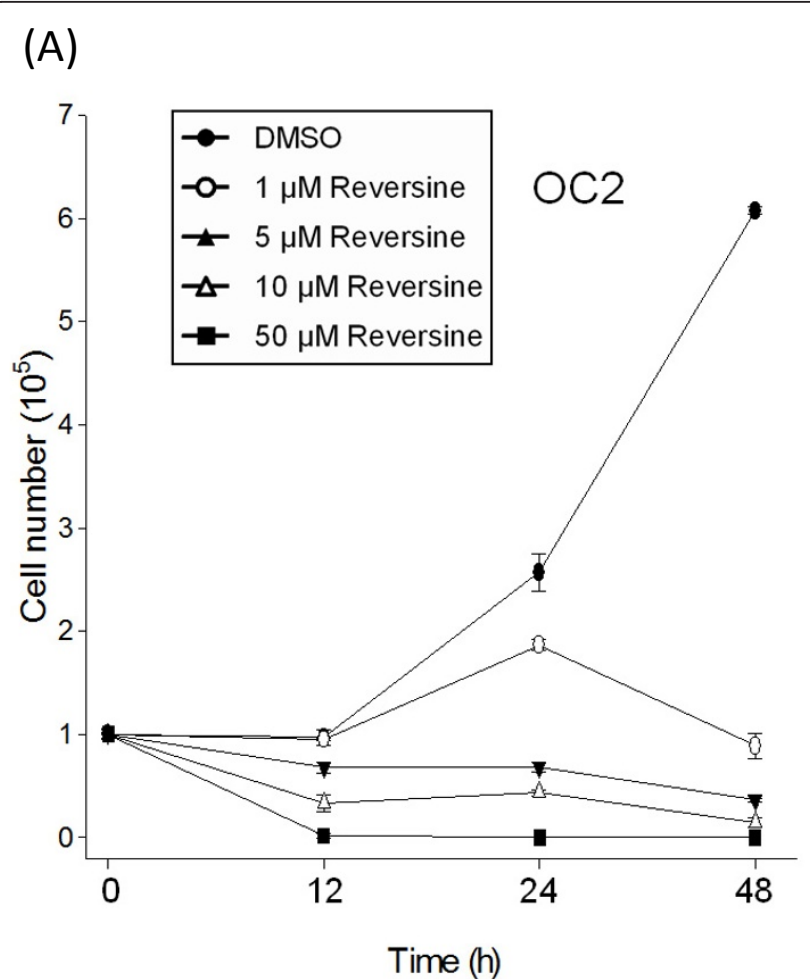

(B)

Figure 1 Reversine suppresses OSCC cell growth. OSCC cells OC2 (A) and OCSL (B) were treated with DMSO or various concentrations of reversine $(1$ to $50 \mu \mathrm{M})$. Cells were harvested, stained by trypan blue and calculated at the 12,24 and $48 \mathrm{~h}$. Data were expressed as means \pm SD of three independent experiments, each of which was done in triplicate.

fifty in OCSL cells after 24 hours treatment. (Figure 3B), highly suggesting that reversine was more effective in OCSL cells, the cell line previously proven more malignant than OC2 [32].

Treatment of reversine obviously resulted in accumulation of cleaved caspase 3 (Figure 3C). This result further confirmed that reversine could suppress cell growth through type I programmed cell death. Both extrinsic and intrinsic pathways are involved in type I programmed cell death. We showed that the cleaved caspase 8 was increased after reversine treatment, indicating the activation of extrinsic pathway [37]. On the other hand, accumulation of processed caspase 9 and decrease of Bcl family members (Bcl-xL and Bid) demonstrated that reversine also enhanced intrinsic pathway. Taken together, these results confirmed that reversine could suppress the oral cell growth through the canonical caspase-dependent pathway.

Z-VAD-fmk, a pan-caspase inhibitor, has been used to check whether drug-induced cell death is through the caspases pathway. Surprisingly, the number of viable cells only slightly increased even after treatment of inhibitor for two days (Figure 4A). It was unlikely due to insufficient concentration of Z-VAD-fmk inhibitor because of the complete inhibition of caspase 3 (Figure 4B). In

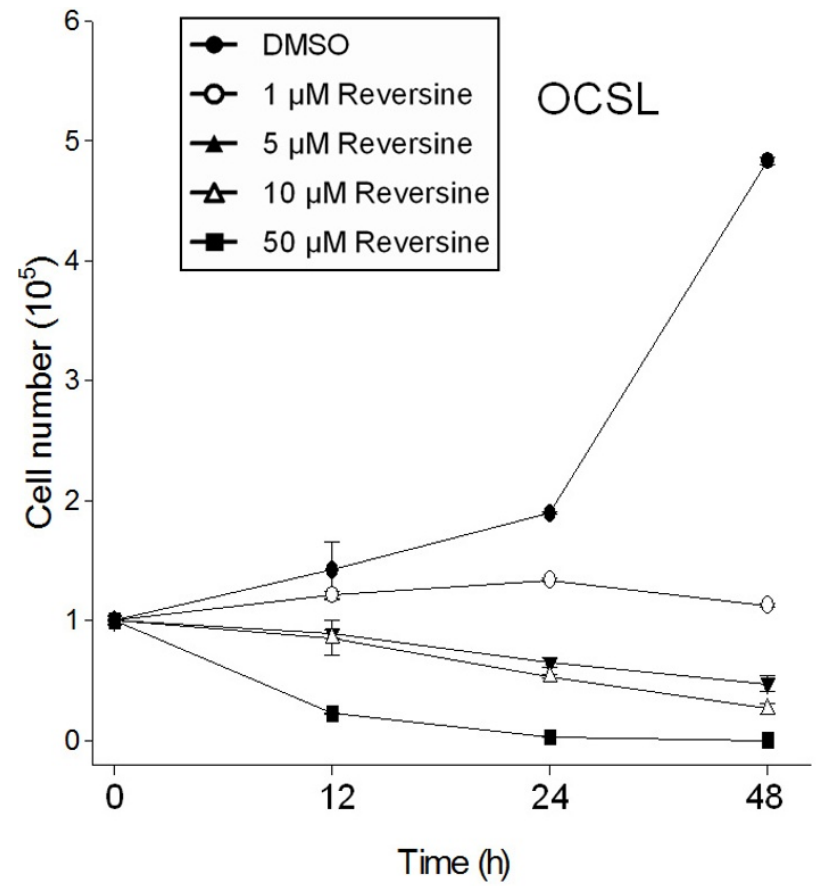

addition, DNA ladder under the treatment of both Z-VAD-fmk and reversine was still observed (Figure 4C). Taken together, these results suggested that reversineinduced cell death was mediated mainly through another caspase-independent programmed cell death. To support these results, we examined the location of AIF in the absence or presence of reversine in OC2 cells. AIF was identified as a marker protein for caspase-independent apoptosis [38,39]. In normal physiological condition, AIF is retained in the mitochondrial membrane, where it executes the oxidoreductase function [40]. Once activated by apoptosis, AIF was translocated into the nucleus from the mitochondrial membrane and causes chromatin condensation and DNA fragmentation [41]. As shown in Figure 4D, AIF was located in the cytoplasm in the absence of reversine. However, after treatment of $5 \mu \mathrm{M}$ reversine for 24 hour, AIF was translocated into the nucleus in $\mathrm{OC} 2$ cells, indicating that reversine can trigger the non-canonical caspase-independent cell death.

\section{Reversine also induces autophagy}

After treatment of reversine, cells showed intracellular vacuoles as shown in Figure 5A, implying that reversine may induce the autophagic responses. We checked whether reversine had an effect on the level of type I 
(A)
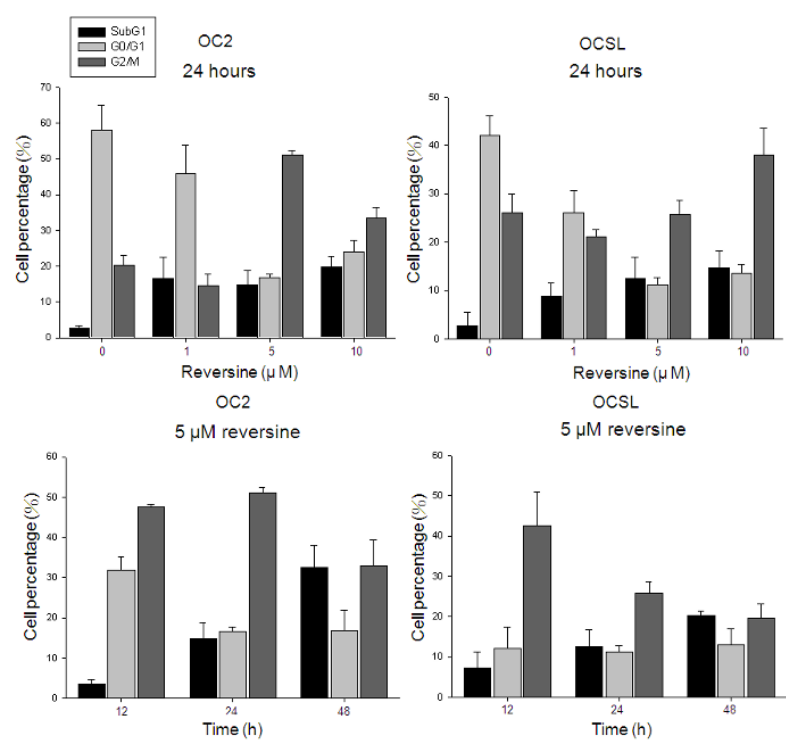

(B)
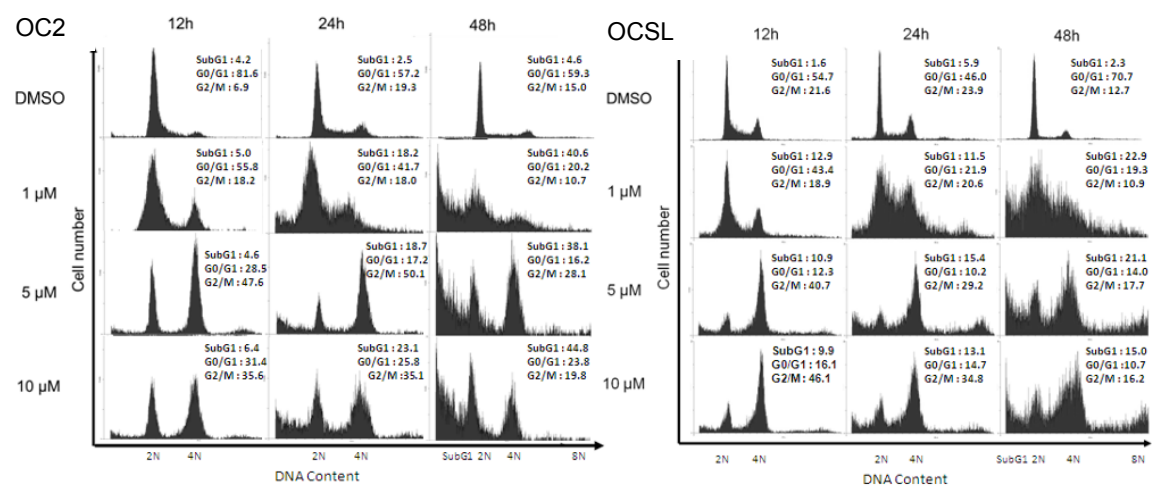

(C)

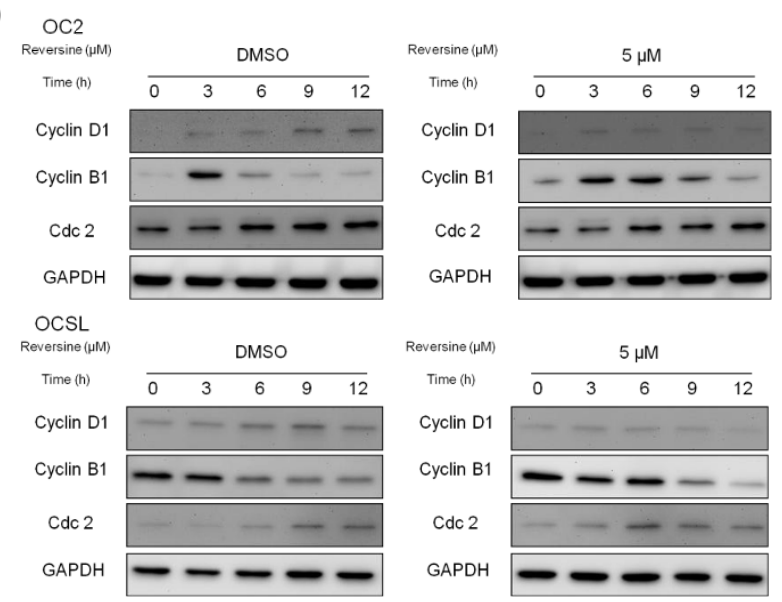

Figure 2 Cell cycle arrests by reversine. (A) OSCC cells were treated with DMSO or different concentrations of reversine $(1,5,10 \mu \mathrm{M})$ for 12 , 24 and $48 \mathrm{~h}$. Cells were harvested, stained with PI and applied for flow cytometry analysis. The data were analyzed from three independent experiments. (B) As in (A), cells were treated with either different doses of reversine at $24 \mathrm{~h}$ or $5 \mu \mathrm{M}$ reversine at indicated time points. The percentage of cells in each phase of the cell cycle was demonstrated. (C) OSCC cells treated with DMSO or $5 \mu$ M reversine were harvested and analyzed for cell cycle-dependent proteins. The GAPDH protein was used as the loading control. 
(A)

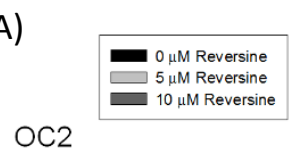

OC2 OCSL
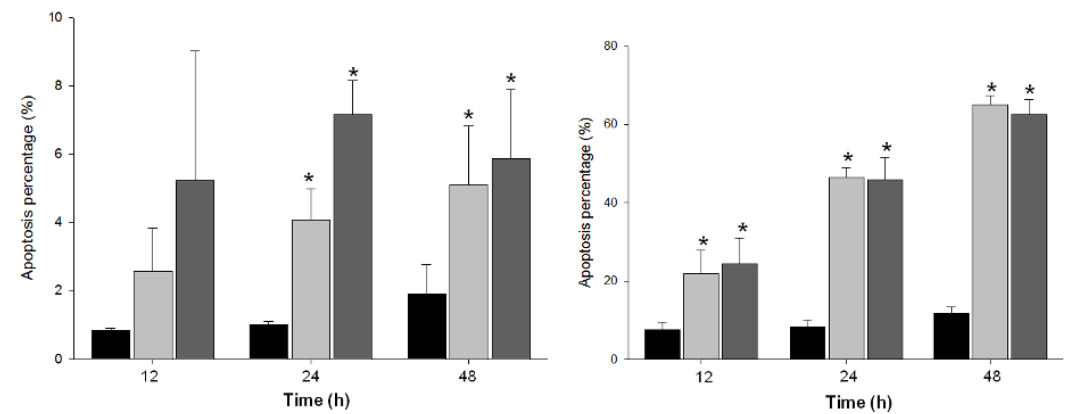

(B)

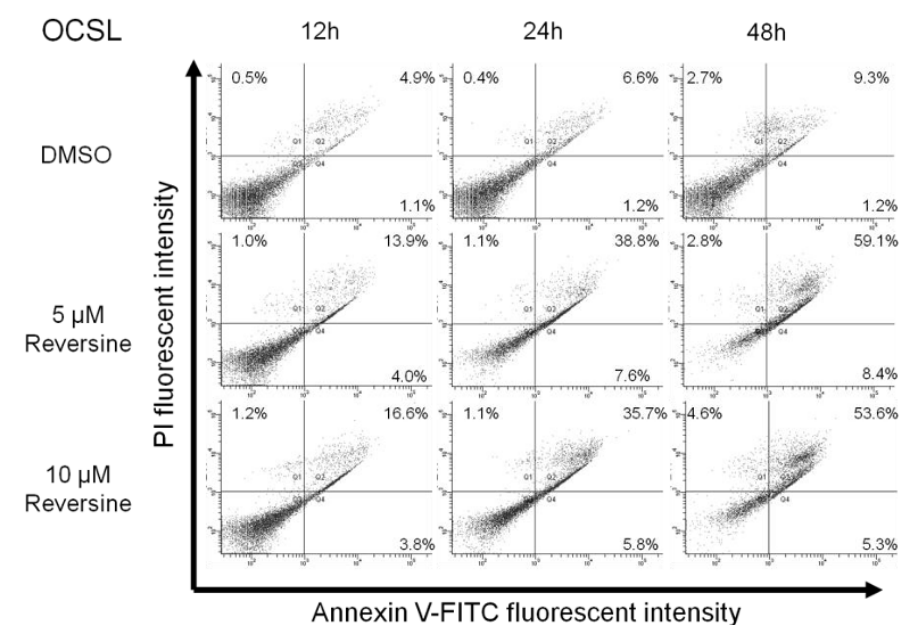

(C)
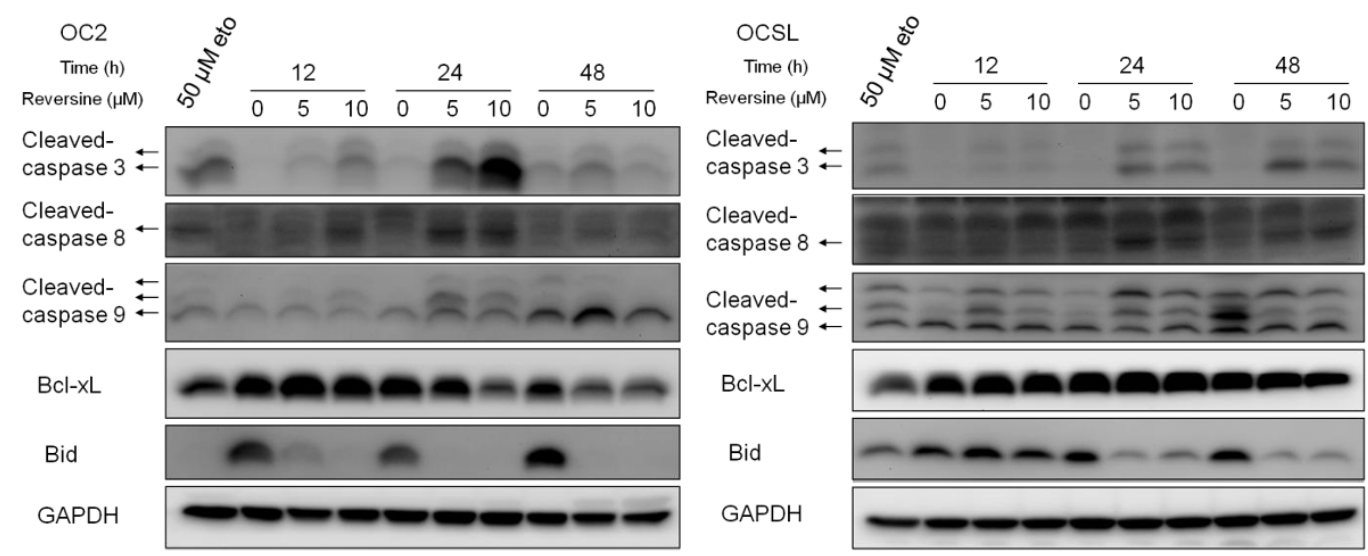

Figure 3 Induction of apoptosis by reversine. (A) OSCC cells were treated with DMSO or different concentrations of reversine ( 5 and $10 \mu \mathrm{M})$. At indicated time points (12, 24 and 48 h), cells were dually stained with annexin V-FITC and PI as described and analyzed by flow cytometry. The percentage of cells in early apoptosis and early apoptosis plus late apoptosis of OC2 and OCSL cells were evaluated, respectively. All results were obtained from three independent experiments. * indicated significant difference from the untreated cells (DMSO) $(p<0.05)$. (B) The representative figure of flow cytometry from OCSL cells treated as described in (A). (C) OSCC cells harvested from (A) were used to analyze the expression of apoptosis-related proteins. Cells treated with $50 \mu \mathrm{M}$ etoposide to induce apoptosis were used as a positive control. 
(A)
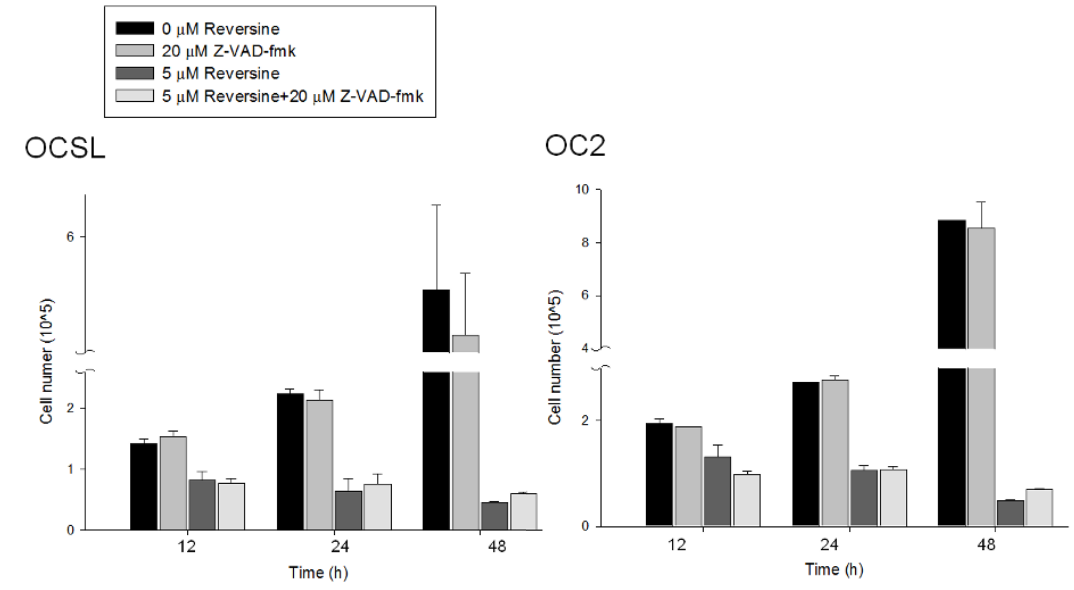

(B)

$$
\text { OC2 }
$$

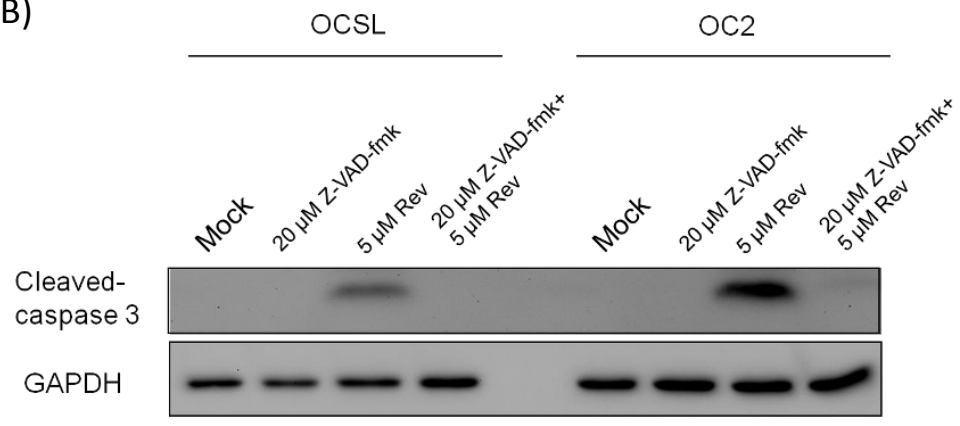

(C)

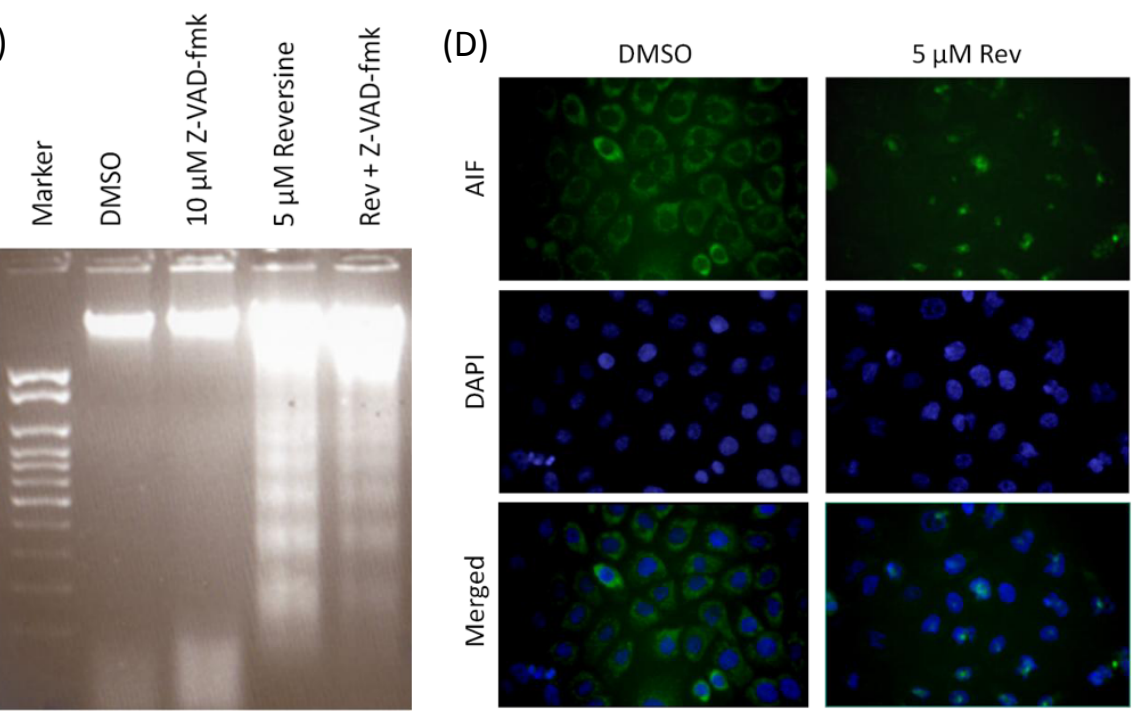

Figure 4 Induction of caspase-independent cell death by reversine. (A) Two hours before reversine addition, OSCC cells were pre-treated with or without $20 \mu \mathrm{M}$ Z-VAD-fmk, followed by treated with or without $5 \mu \mathrm{M}$ reversine, and harvested at 12, 24 and $48 \mathrm{~h}$ later. Cell numbers were counted as mentioned. (B) OSCC cells in (A) panel at 24th hour were used to monitor the cleaved caspase 3 protein as a marker of caspase-dependent apoptosis. (C) Similar to (B) panel, OC2 cells were used for DNA fragmentation analysis. (D) OC2 cells were treated with $5 \mu \mathrm{M}$ reversine, stained with anti-AIF antibody and DAPI and visualized with a fluorescence microscope (magnification, $\times 200$ ). AIF was retained in the cytoplasm in the absence of reversine and translocated into the nucleus after reversine treatment. 
(A)

DMSO

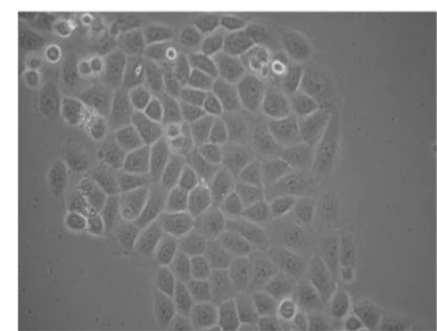

$5 \mu \mathrm{M}$ Rev



(C)


DMSO
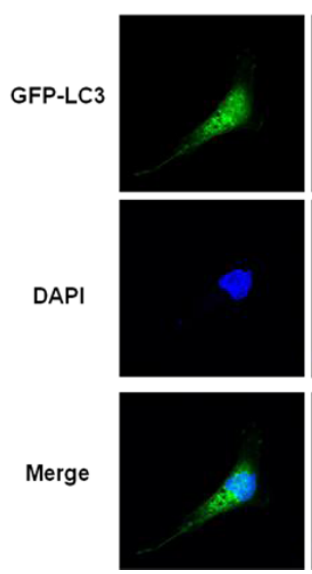
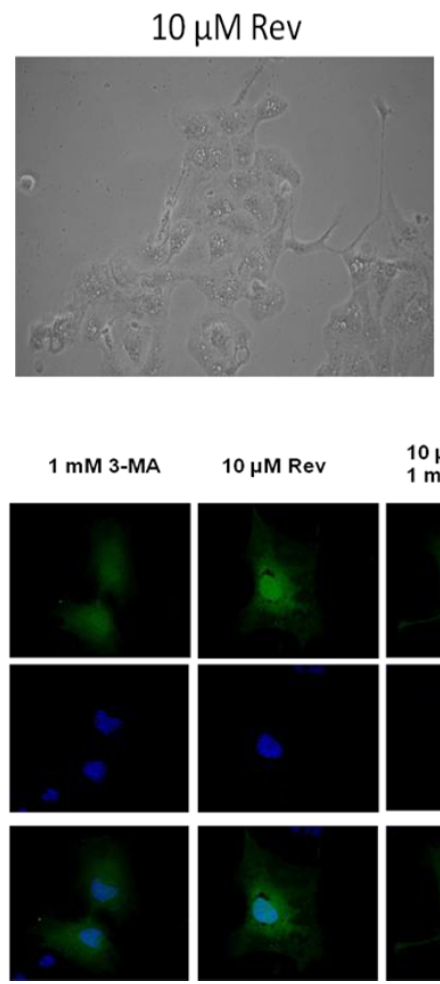

$1 \mathrm{mM}$ 3-MA
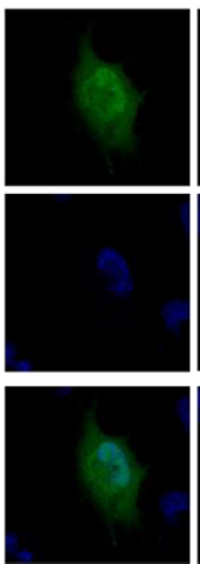

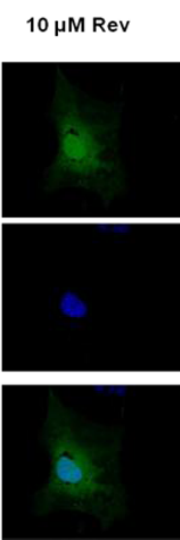

$10 \mu \mathrm{M} R e v$
$1 \mathrm{mM}$ 3-MA

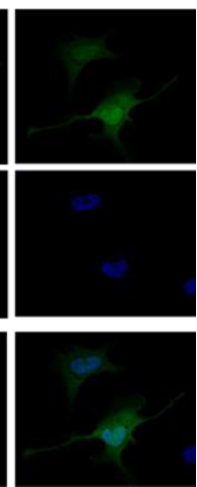

$10 \mu \mathrm{M}$ Rev + 1 mM 3-MA
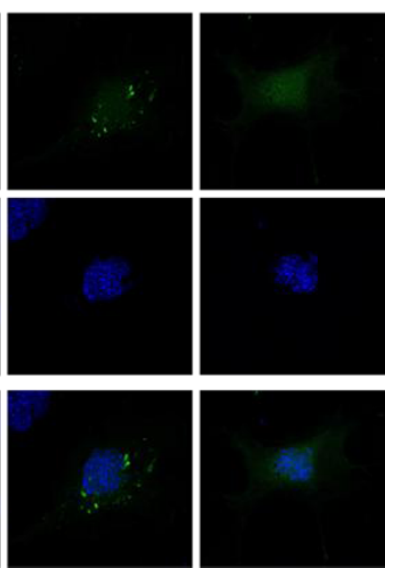

Figure $\mathbf{5}$ Induction of autophagy by reversine. (A) OC2 cells were treated without (DMSO) or with reversine (5 and $10 \mu \mathrm{M})$ for $24 \mathrm{~h}$. Phasecontrast microscopy were taken with 200x magnification. Autophagic vesicles were observed in cells treated with reversine. (B) OSCC cells were pre-treated with 1 or 3 mM 3-MA for 2 hours, followed by treatment without or with $10 \mu \mathrm{M}$ reversine. At indicated time points, cells were harvested for analyzing the cytoplasmic form LC3-I or the membrane form LC3-II. (C) OCSL cells were transfected with vectors expressing either GFP or GFP-LC3-II, followed by treatment of 3-MA and/or reversine as described. OSCL cells were analyzed under confocal microscope. (D) The same as (C) except that two different concentrations of 3-MA were evaluated. The percentages of cells with puncta were calculated by examining over 100 GFP positive cells. All values were expressed as means \pm SD of three independent experiments, each of which was done in triplicate. 
and II LC3 (LC3-II). LC3-II increased obviously within 12 hours after reversine treatment both in $\mathrm{OC} 2$ and OCSL cells (Figure 5B). Interestingly, the pattern of LC3 in OC2 and OCSL cells under normal condition was different. Even without reversine stimulation, OC2 cells showed endogenous LC3-II expression. Unlike in OC2, the effect of reversine on LC3-II in OCSL cells was more significant. Co-treatment of the autophagy inhibitor 3-MA decreased reversine-induced LC3-II in both cells, especially in OCSL cells (Figure 5B). This result indicated that reversine could trigger autophagy and might contribute to the caspase-independent programmed cell death. This possibility was further confirmed by the effect of reversine in LC3-II aggregation: In OCSL cells ectopically expressing GFP-LC3. GFPLC3 showed diffuse pattern but became puncta pattern if treated with reversine (Figure $5 \mathrm{C}$ ). This puncta pattern was not observed in the control cells harboring GFP plasmid only in the presence of reversine or 3-MA, ruling out the possibility of non-specific effects of the drugs on puncta formation. Moreover, this puncta pattern was totally abolished if co-treatment reversine with autophagy inhibitor 3-MA (Figure 5C). The quantitative results are shown in Figure 5D. These data confirmed that reversine triggered autophagic flux in OSCC cells.

\section{Reversine inhibits Akt/mTOR signaling pathway}

Previous studies demonstrated that deregulation of PI3K-Akt signaling was frequently observed in various cancer cells including OSCC. For example, over-activation of Akt may enhance malignancy and resistance of cancer cells through anti- apoptotic stress [42]. Therefore, PI3K-Akt pathway became a promising target for cancer therapy recently [43]. In addition, aurora kinases were also proven as an upstream regulator of Akt activity in several cancers recently [44]. Since reversine was an inhibitor of aurora kinase, the effect of reversine on Akt activity deserved further investigations. As expected, reversine notably reduced the phosphorylation of Akt as well as downstream factors, including mTOR complex 1 (mTORC1) and p70S6K within 12 hours (Figure 6). On the contrary, although phospho-Jnk was affected slightly at later time, reversine showed no significant influence on the activation of MAPKs pathway (Additional file 2). These results indicated that reversine selectively downregulated Akt/mTORC1 signaling pathway, resulting in the suppression of cancer cell growth and induction of autophagy.

\section{Discussion}

Our previous studies have characterized two OSCC cell lines, OC2 and OCSL, which were established from buccal specimens of two Taiwanese male patients with habit of betel-quid chewing. The OCSL cells showed greater

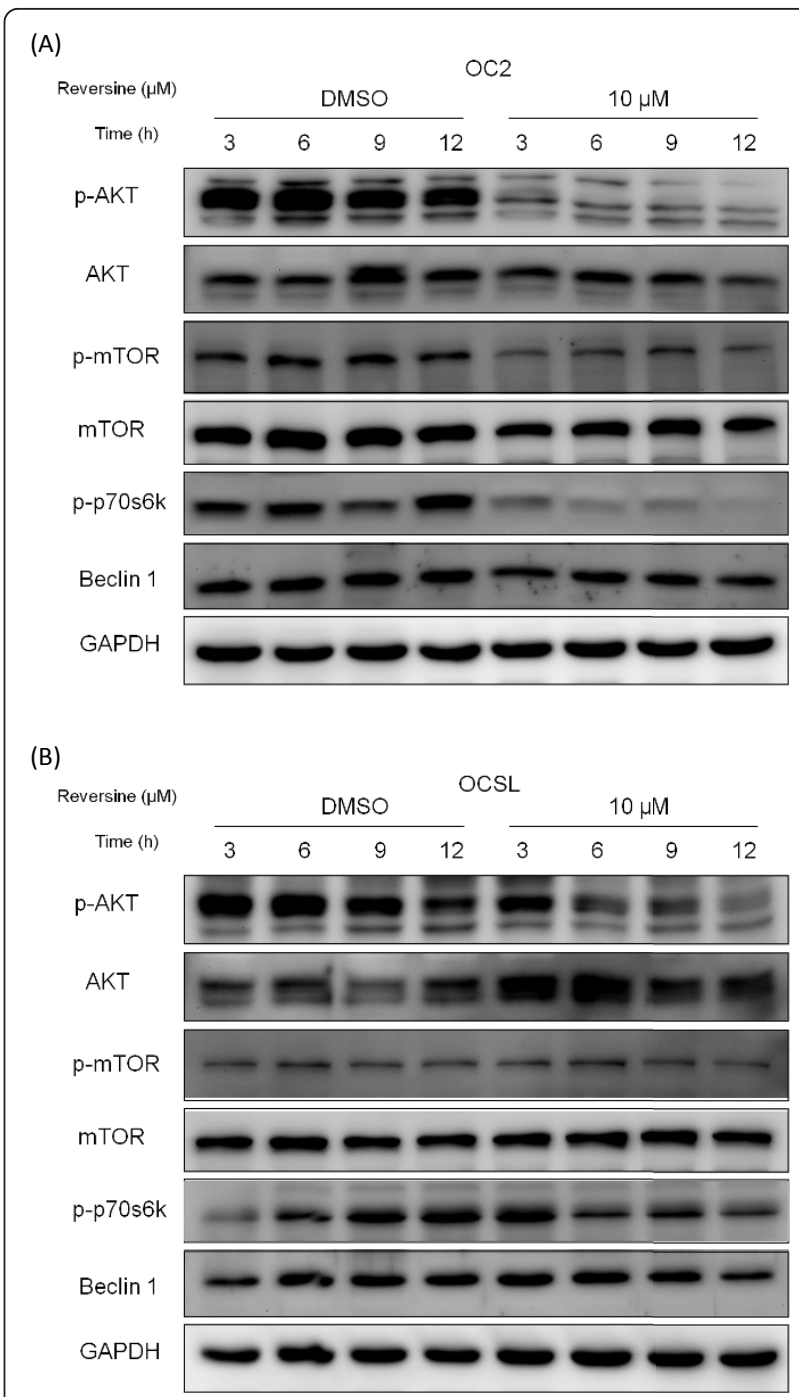

Figure 6 Downregulation of Akt/mTORC1 signaling pathway by reversine. OC2 cells (A) and OCSL cells (B) were treated with DMSO or $10 \mu \mathrm{M}$ reversine and harvested at indicated time points for analyzing the indicated proteins, such as AKT, mTOR, p70S6K and Beclin.

proliferation, horizontal and vertical migration, and transwell invasion abilities in comparison with OC2 cells [32]. In this study, we demonstrated that reversine suppressed the growth of these two OSCC cells. One of the mechanisms for such suppression is that reversine retards cell cycle at $\mathrm{G} 2 / \mathrm{M}$ stage, which was evidenced by the prolonged expression of cyclin B1. This was also observed in the treatment of another aurora kinase inhibitor VX680 in HeLa cells [25,45]. However, we found that cyclin B1 decreased later in the treatment concurrently with an increased level of cyclin D (Figure 2C). This allows the cells to re-enter G1 phase, subsequently leading to $4 \mathrm{~N}$ or even $8 \mathrm{~N}$ chromosome content in OCSL cells (Figure 2B). Increase of polyploidy cells 
indicated the continuous DNA synthesis with unsuccessful cytokinesis. Consistent with this are growth arrest and polyploidy observed in HeLa, CWR22Rv1, DU-145 and HCT-116 cells after reversine treatment $[25,30,46]$.

We also demonstrated that reversine can trigger apoptosis, especially in the malignant OCSL cells (Figure $3 \mathrm{~A})$. The detail mechanism by which reversine triggers apoptosis remains unclear. However, we noticed that the amount of phosphorylated aurora kinases was slightly higher in OC2 than that in OCSL (Additional File 1, Figure S1). Previous study showed that aurora kinase A overexpression can override the mitotic spindle assembly checkpoint and induce resistance to taxol [47]. This study may explain why $\mathrm{OC} 2$ is more resistant to reversine. Moreover, VX680 selectively kills cells that overexpress c-myc. In other words, VX680 is more efficient to induce apoptosis in cells in a c-myc dependent but p53 independent manner [23]. In OSCC, p53 mutation and c-myc amplification were observed [48]. In OC2 and OCSL cells, both have mutated p53 but have the similar level of c-myc [49 and our unpublished date]. However, we did not rule out the possibility that these two OSCC cells potentially have mutated c-myc with different activity. Furthermore, inhibitor of aurora kinase B, ZM447439, suppresses the growth of cervical cancer $\mathrm{SiHa}$ cells and enhances the chemosensitivity to Cisplatin [50]. These studies provided the hint why OCSL was more sensitive to reversine.

Aurora kinases had been reported to participate in several signaling pathways like PI3K-Akt [44]. Here we show that reversine may inhibit the activity of Akt, which is frequently over-activated in many cancers $[42,43]$. Besides, mTORC1, the downstream factor of Akt, is also critical for cell proliferation and correlated to carcinogenesis [51]. Actually, mTORC1 phosphorylates $4 \mathrm{E}-\mathrm{BP} 1$ to release eIF4E and affects the phosphorylation of ribosomal protein S6 through p70S6K [52]. Therefore, $\mathrm{mTORC} 1$ functions as a regulator for protein synthesis [53]. Interestingly, although reversine affects the activities of mTORC1 pathway, its final influence on translation machinery is not global based on the constant expression of Beclin 1 (Figure 6A). How the specificity was regulated still remains unclear.

In addition to proteins translation pathway, the role of mTORC1 is correlated to autophagy control [54]. Like double-edged sword, autophagy could have opposite effects on tumor cells [55]. Modest autophagy may help neoplasia cells survive under harsh environments $[56,57]$. Autophagy could play the protective role that impedes the cell death by reducing the occurrence of intrinsic apoptosis through mitochondria consumption $[58,59]$. On the contrary, autophagy was also reported to be disadvantageous for cancer cells [55-57]. Therefore, several autophagy-based chemicals are being tested for cancer therapy [60]. Our results showed that reversine enhances autophagy significantly in malignant OCSL cells, but weakly in less-malignant OC2 (Figure 5B). Figure $3 \mathrm{~A}$ also suggested that reversine triggered apoptosis more effectively in OCSL cells. These discrepancies may be also suitable for differentiation between normal cells and cancer cells, which will be a tremendous advantage for the clinical application. Even under normal culture condition, we noticed that OC2 cells have high level of endogenous autophagy based on the constitutive expression of LC3-II (Figure 5B). Since OC2 cells is a less malignant cell line with the characteristics of squamous cells, it is highly possible that original OC2 cells may take advantage of high basal autophagy to survive before sufficient nutrients supply by angiogenesis in early carcinogenesis stage in vivo. Interestingly, inhibition of mTORC1 by rapamycin induces no significant increase of LC3-II in OCSL cells (data not shown), suggesting other unknown pathways involved in this reversineinduced autophagy in OCSL cells. The exact mechanism for reversine-induced autophagy in OCSL cells deserved to be verified.

Because several cancer cells were reported to have mutations such as p53 and caspases to enhance resistance against apoptotic stress, a multi-targeting strategy against tumor cells may increase the chance to treat cancers [61-65]. Here, we demonstrated that reversine is a broad-spectrum antitumor agent that induces cell cycle arrest, apoptosis, caspase-independent death and autophagy, suggesting that either reversine itself or reversine in combination with other drugs is a novel therapeutic regimen for OSCC patients.

\section{Conclusions}

Oral cancer is one of the leading cancers in Taiwan due to betel quid chewing. However, current chemotherapy using Cisplatin and 5-Fu against OSCC remains inefficient to improve survival rate. Reversine suppresses OSCC cells via multiple mechanisms, which may provide a new way advantageous for treating oral cancer. Based on this study, evaluations of cellular sensitivity/ resistance to reversine itself or reversine in combination with the current drugs Cisplatin and 5-Fu in cell culture and in animal xenografts model deserve to be further tested in the future.

\section{Additional material}

\footnotetext{
Additional file 1: Inhibition of aurora kinases activities by reversine. (A) Aurora kinases were detectable in two OSCC cell lines, OC2 and OCSL. (B) Reversine inhibited Serine 10 phosphorylation of histone $\mathrm{H} 3$ in OSCC cells. Nocodazole treatment was used as a positive control.

Additional file 2: No significant influence on the activation of MAPKs pathway by reversine. MAPK signaling pathway was not changed significantly in reversine-induced cell death. Proteins involved in
} 
this pathway, such as MAPK, Jnk and Erk were examined in OC2 and OCSL cells, respectively. The GAPDH protein was used as the loading control.

\section{Acknowledgements}

The authors would like to thank Mr. Chun-Jen Wang for technical assistance and Dr. N. Mizushima and Dr. T. Yoshimori for providing the GFP-LC3 plasmid. This work was supported by National Science Council (97-2311-B194-001-MY3) and (NSC-99-2314-B-705-002-MY2).

\section{Author details}

'Department of Medical Research, Chiayi Christian Hospital, Chia-Yi, Taiwan. ${ }^{2}$ Department of Nursing, Min-Hwei College of Health Care Management, Tainan, Taiwan. ${ }^{3}$ Department of Life Science, Institute of Molecular Biology and Institute of Biomedical Science, College of Science, National Chung Cheng University, Min-Hsiung, Chia-Yi, Taiwan. ${ }^{4}$ Department of Biotechnology, Kaohsiung Medical University, Kaohsiung, Taiwan.

\section{Authors' contributions}

YRL initiated this project and paved the fundamental frame of this project. WCW executed most of the experiments. WTJ performed the Figure 4D, Figure $5 \mathrm{~A}$ as well as additional file $1 \mathrm{~B}$ and was responsible for writing the partial sections of the manuscript. JYFC conceived the plan. YPC and MKC finished the Figure $4 \mathrm{C}$. HRC wrote the manuscript. All authors read and approved the final manuscript.

\section{Competing interests}

The authors declare that they have no competing interests.

Received: 21 December 2011 Accepted: 27 January 2012

Published: 27 January 2012

\section{References}

1. Ng SH, Yen TC, Liao CT, Chang JT, Chan SC, Ko SF, Wang HM, Wong HF: 18F-FDG PET and CT/MRI in oral cavity squamous cell carcinoma: a prospective study of 124 patients with histologic correlation. J Nucl Med 2005, 46:1136-1143.

2. Chung TT, Pan MS, Kuo CL, Wong RH, Lin CW, Chen MK, Yang SF: Impact of RECK gene polymorphisms and environmental factors on oral cancer susceptibility and clinicopathologic characteristics in Taiwan. Carcinogenesis 2011, 32:1063-1068.

3. Chen YK, Huang HC, Lin LM, Lin CC: Primary oral squamous cell carcinoma: an analysis of 703 cases in southern Taiwan. Oral Oncology 1999, 35:173-179.

4. Jemal A, Bray F, Center MM, Ferlay J, Ward E, Forman D: Global Cancer Statistics. Ca-a Cancer Journal for Clinicians 2011, 61:69-90.

5. Trivedy $C R$, Craig G, Warnakulasuriya $S$ : The oral health consequences of chewing areca nut. Addiction Biology 2002, 7:115-125.

6. Andreadis C, Vahtsevanos K, Sidiras T, Thomaidis I, Antoniadis K, Mouratidou D: 5-Fluorouracil and cisplatin in the treatment of advanced oral cancer. Oral Oncology 2003, 39:380-385.

7. Okamura M, Kobayashi M, Suzuki F, Shimada J, Sakagami H: Induction of cell death by combination treatment with cisplatin and 5-fluorouracil in a human oral squamous cell carcinoma cell line. Anticancer Research 2007, 27:3331-3337.

8. Fu J, Bian M, Jiang Q, Zhang C: Roles of Aurora kinases in mitosis and tumorigenesis. Mol Cancer Res 2007, 5:1-10.

9. Seki A, Coppinger JA, Jang CY, Yates JR, Fang G: Bora and the kinase Aurora a cooperatively activate the kinase Plk1 and control mitotic entry. Science 2008, 320:1655-1658.

10. Gautschi O, Heighway J, Mack PC, Purnell PR, Lara PN, Gandara DR: Aurora kinases as anticancer drug targets. Clinical Cancer Research 2008, 14:1639-1648

11. Lens SMA, Voest EE, Medema RH: Shared and separate functions of pololike kinases and aurora kinases in cancer. Nature Reviews Cancer 2010, 10:825-841.

12. Vader G, Lens SM: The Aurora kinase family in cell division and cancer. Biochim Biophys Acta 2008, 1786:60-72.
13. Steigemann P, Wurzenberger C, Schmitz MH, Held M, Guizetti J, Maar S, Gerlich DW: Aurora B-mediated abscission checkpoint protects against tetraploidization. Cell 2009, 136:473-484.

14. Qi G, Kudo Y, Ando T, Tsunematsu T, Shimizu N, Siriwardena SB, Yoshida M, Keikhaee MR, Ogawa I, Takata T: Nuclear Survivin expression is correlated with malignant behaviors of head and neck cancer together with Aurora-B. Oral Oncol 2010, 46:263-270.

15. Ben Khelifa M, Zouari R, Harbuz R, Halouani L, Arnoult C, Lunardi J, Ray PF: A new AURKC mutation causing macrozoospermia: implications for human spermatogenesis and clinical diagnosis. Mol Hum Reprod 2011, 17:762-768.

16. Kimmins S, Crosio C, Kotaja N, Hirayama J, Monaco L, Hoog C, van Duin M, Gossen JA, Sassone-Corsi P: Differential functions of the Aurora-B and Aurora-C kinases in mammalian spermatogenesis. Mol Endocrinol 2007, 21:726-739.

17. Meraldi P, Honda R, Nigg EA: Aurora kinases link chromosome segregation and cell division to cancer susceptibility. Curr Opin Genet Dev 2004, 14:29-36.

18. Qi GY, Ogawa I, Kudo Y, Miyauchi M, Siriwardena BSMS, Shimamoto F, Tatsuka M, Takata T: Aurora-B expression and its correlation with cell proliferation and metastasis in oral cancer. Virchows Archiv 2007, 450:297-302.

19. Kao SY, Chen YP, Tu HF, Liu CJ, Yu AH, Wu CH, Chang KW: Nuclear STK15 expression is associated with aggressive behaviour of oral carcinoma cells in vivo and in vitro. J Pathol 2010, 222:99-109.

20. Dutertre $S$, Hamard-Peron E, Cremet JY, Thomas Y, Prigent C: The absence of p53 aggravates polyploidy and centrosome number abnormality induced by Aurora-C overexpression. Cell Cycle 2005, 4:1783-1787.

21. Gizatullin F, Yao Y, Kung V, Harding MW, Loda M, Shapiro GI: The Aurora kinase inhibitor VX-680 induces endoreduplication and apoptosis preferentially in cells with compromised p53-dependent postmitotic checkpoint function. Cancer Research 2006, 66:7668-7677.

22. Carpinelli P, Ceruti R, Giorgini ML, Cappella P, Gianellini L, Croci V, Degrassi A, Texido G, Rocchetti M, Vianello P, et al: PHA-739358, a potent inhibitor of Aurora kinases with a selective target inhibition profile relevant to cancer. Mol Cancer Ther 2007, 6:3158-3168.

23. Yang D, Liu H, Goga A, Kim S, Yuneva M, Bishop JM: Therapeutic potential of a synthetic lethal interaction between the MYC proto-oncogene and inhibition of aurora-B kinase. Proc Natl Acad Sci USA 2010, 107:13836-13841.

24. Mizushima N: Autophagy: process and function. Genes Dev 2007, 21:2861-2873.

25. Harrington EA, Bebbington D, Moore J, Rasmussen RK, Ajose-Adeogun AO, Nakayama T, Graham JA, Demur C, Hercend T, Diu-Hercend A, et al: VX680, a potent and selective small-molecule inhibitor of the Aurora kinases, suppresses tumor growth in vivo. Nat Med 2004, 10:262-267.

26. Amabile $G$, D'Alise AM, lovino $M$, Jones $P$, Santaguida $S$, Musacchio $A$, Taylor S, Cortese R: The Aurora B kinase activity is required for the maintenance of the differentiated state of murine myoblasts. Cell Death and Differentiation 2009, 16:321-330.

27. Lee EK, Bae GU, You JS, Lee JC, Jeon YJ, Park JW, Park JH, Ahn SH, Kim YK, Choi WS, et al: Reversine Increases the Plasticity of Lineage-committed Cells toward Neuroectodermal Lineage. Journal of Biological Chemistry 2009, 284:2891-2901.

28. Mountzios G, Terpos E, Dimopoulos MA: Aurora kinases as targets for cancer therapy. Cancer Treatment Reviews 2008, 34:175-182.

29. D'Alise AM, Amabile G, lovino M, Di Giorgio FP, Bartiromo M, Sessa F, Villa F, Musacchio A, Cortese R: Reversine, a novel Aurora kinases inhibitor, inhibits colony formation of human acute myeloid leukemia cells. Mol Cancer Ther 2008, 7:1140-1149.

30. Hsieh TC, Traganos F, Darzynkiewicz Z, Wu JM: The 2,6-disubstituted purine reversine induces growth arrest and polyploidy in human cancer cells. Int J Oncol 2007, 31:1293-1300.

31. Labrada L, Bodelon G, Vinuela J, Benavente J: Avian reoviruses cause apoptosis in cultured cells: viral uncoating, but not viral gene expression, is required for apoptosis induction. J Virol 2002, 76:7932-7941.

32. Huang $T$, Chen JY, Tseng CE, Su YC, Ho HC, Lee MS, Chang CT, Wong YK, Chen HR: Decreased GRP78 protein expression is a potential prognostic marker of oral squamous cell carcinoma in Taiwan. J Formos Med Assoc 2010, 109:326-337. 
33. Crosio C, Fimia GM, Loury R, Kimura M, Okano Y, Zhou H, Sen S, Allis CD, Sassone-Corsi P: Mitotic phosphorylation of histone H3: spatio-temporal regulation by mammalian Aurora kinases. Mol Cell Biol 2002, 22:874-885.

34. Chefetz I, Holmberg JC, Alvero AB, Visintin I, Mor G: Inhibition of Aurora-A kinase induces cell cycle arrest in epithelial ovarian cancer stem cells by affecting NFkB pathway. Cell Cycle 2011, 10:2206-2214.

35. Li Y, Zhang ZF, Chen J, Huang D, Ding Y, Tan MH, Qian CN, Resau JH, Kim H, Teh BT: VX680/MK-0457, a potent and selective Aurora kinase inhibitor, targets both tumor and endothelial cells in clear cell renal cell carcinoma. Am J Transl Res 2010, 2:296-308.

36. Lin ZZ, Hsu HC, Hsu CH, Yeh PY, Huang CY, Huang YF, Chen TJ, Kuo SH, Hsu C, Hu FC, et al: The Aurora kinase inhibitor VE-465 has anticancer effects in pre-clinical studies of human hepatocellular carcinoma. $J$ Hepatol 2009, 50:518-527.

37. Elmore S: Apoptosis: a review of programmed cell death. Toxicol Pathol 2007, 35:495-516.

38. Joza N, Susin SA, Daugas E, Stanford WL, Cho SK, Li CY, Sasaki T, Elia AJ, Cheng HY, Ravagnan L, et al: Essential role of the mitochondrial apoptosis-inducing factor in programmed cell death. Nature 2001, 410:549-554

39. Susin SA, Zamzami N, Castedo M, Hirsch T, Marchetti P, Macho A, Daugas E, Geuskens M, Kroemer G: Bcl-2 inhibits the mitochondrial release of an apoptogenic protease. J Exp Med 1996, 184:1331-1341.

40. Miramar MD, Costantini P, Ravagnan L, Saraiva LM, Haouzi D, Brothers G, Penninger JM, Peleato ML, Kroemer G, Susin SA: NADH oxidase activity of mitochondrial apoptosis-inducing factor. J Biol Chem 2001, 276:16391-16398.

41. Cande C, Cecconi F, Dessen P, Kroemer G: Apoptosis-inducing factor (AIF): key to the conserved caspase-independent pathways of cell death? J Cell Sci 2002, 115:4727-4734.

42. Fresno Vara JA, Casado E, de Castro J, Cejas P, Belda-Iniesta C, GonzalezBaron M: PI3K/Akt signalling pathway and cancer. Cancer Treat Rev 2004, 30:193-204.

43. Luo J, Manning BD, Cantley LC: Targeting the PI3K-Akt pathway in human cancer: rationale and promise. Cancer Cell 2003, 4:257-262.

44. Xu DR, Huang S, Long ZJ, Chen JJ, Zou ZZ, Li J, Lin DJ, Liu Q: Inhibition of mitotic kinase Aurora suppresses Akt-1 activation and induces apoptotic cell death in all-trans retinoid acid-resistant acute promyelocytic leukemia cells. Journal of Translational Medicine 2011, 9.

45. Benten D, Keller G, Quaas A, Schrader J, Gontarewicz A, Balabanov S, Braig M, Wege H, Moll J, Lohse AW, et al: Aurora kinase inhibitor PHA739358 suppresses growth of hepatocellular carcinoma in vitro and in a xenograft mouse model. Neoplasia 2009, 11:934-944.

46. Perreira M, Jiang JK, Klutz AM, Gao ZG, Shainberg A, Lu C, Thomas CJ, Jacobson KA: "Reversine" and its 2-substituted adenine derivatives as potent and selective $A 3$ adenosine receptor antagonists. $J$ Med Chem 2005, 48:4910-4918.

47. Anand S, Penrhyn-Lowe S, Venkitaraman AR: AURORA-A amplification overrides the mitotic spindle assembly checkpoint, inducing resistance to Taxol. Cancer Cell 2003, 3:51-62.

48. Martin-Ezquerra G, Salgado R, Toll A, Gilaberte M, Baro T, Alameda Quitllet F, Yebenes M, Sole F, Garcia-Muret M, Espinet B, et al: Multiple genetic copy number alterations in oral squamous cell carcinoma: study of MYC, TP53, CCDN1, EGFR and ERBB2 status in primary and metastatic tumours. Br J Dermatol 2010, 163:1028-1035.

49. Fan LC, Chiang WF, Liang CH, Tsai YT, Wong TY, Chen KC, Hong TM, Chen YL: alpha-Catulin knockdown induces senescence in cancer cells. Oncogene 2011, 30:2610-2621.

50. Zhang L, Zhang S: ZM447439, the Aurora kinase B inhibitor, suppresses the growth of cervical cancer SiHa cells and enhances the chemosensitivity to cisplatin. J Obstet Gynaecol Res 2011, 37:591-600.

51. Mamane Y, Petroulakis E, LeBacquer O, Sonenberg N: mTOR, translation initiation and cancer. Oncogene 2006, 25:6416-6422.

52. Sarbassov DD, Ali SM, Sabatini DM: Growing roles for the mTOR pathway. Curr Opin Cell Biol 2005, 17:596-603.

53. Wang $X$, Proud CG: The mTOR pathway in the control of protein synthesis. Physiology (Bethesda) 2006, 21:362-369.

54. Jung $\mathrm{CH}$, Ro SH, Cao J, Otto NM, Kim DH: mTOR regulation of autophagy. FEBS Lett 2010, 584:1287-1295.

55. Hippert MM, O'Toole PS, Thorburn A: Autophagy in cancer: Good, bad, or both? Cancer Research 2006, 66:9349-9351.
56. Thorburn A: Studying autophagy's relationship to cell death. Autophagy 2008, 4:391-394

57. Gump JM, Thorburn A: Autophagy and apoptosis: what is the connection? Trends Cell Biol 2011, 21:387-392.

58. Yang $Y$, Xing D, Zhou FF, Chen Q: Mitochondrial autophagy protects against heat shock-induced apoptosis through reducing cytosolic cytochrome $\mathrm{c}$ release and downstream caspase-3 activation. Biochemical and Biophysical Research Communications 2010, 395:190-195.

59. Kondo Y, Kondo S: Autophagy and cancer therapy. Autophagy 2006, 2:85-90.

60. Notte A, Leclere L, Michiels C: Autophagy as a mediator of chemotherapy-induced cell death in cancer. Biochemical Pharmacology 2011, 82:427-434.

61. Soussi T, Lozano G: p53 mutation heterogeneity in cancer. Biochemical and Biophysical Research Communications 2005, 331:834-842.

62. Park WS, Lee JH, Shin MS, Park JY, Kim HS, Lee JH, Kim YS, Lee SN, Xiao WH, Park $\mathrm{CH}$, et al: Inactivating mutations of the caspase-10 gene in gastric cancer. Oncogene 2002, 21:2919-2925.

63. Soung YH, Lee JW, Kim SY, Jang J, Park YG, Park WS, Nam SW, Lee JY, Yoo NJ, Lee SH: CASPASE-8 gene is inactivated by somatic mutations in gastric carcinomas. Cancer Research 2005, 65:815-821.

64. Soung YH, Lee JW, Kim SY, Sung YJ, Park WS, Nam SW, Kim SH, Lee JY, Yoo NJ, Lee SH: Caspase- 8 gene is frequently inactivated by the frameshift somatic mutation 1225_1226delTG in hepatocellular carcinomas. Oncogene 2005, 24:141-147.

65. You J, He Z, Chen L, Deng G, Liu W, Qin L, Qiu F, Chen X: CH05-10, a novel indinavir analog, is a broad-spectrum antitumor agent that induces cell cycle arrest, apoptosis, endoplasmic reticulum stress and autophagy. Cancer Sci 2010, 101:2644-2651.

doi:10.1186/1423-0127-19-9

Cite this article as: Lee et al.: Reversine suppresses oral squamous cell carcinoma via cell cycle arrest and concomitantly apoptosis and autophagy. Journal of Biomedical Science 2012 19:9.

\section{Submit your next manuscript to BioMed Central and take full advantage of:}

- Convenient online submission

- Thorough peer review

- No space constraints or color figure charges

- Immediate publication on acceptance

- Inclusion in PubMed, CAS, Scopus and Google Scholar

- Research which is freely available for redistribution

Submit your manuscript at www.biomedcentral.com/submit
C Biomed Central 